\title{
SENSITIZATION OF PARKER FITTINGS
}

HEDL- -7553

DE85 018506

W.W. Wilber

Date Published: September 1985

\section{DISCLAIMER}

This report was prepared as an account of work sponsored by an agency of the United States Government. Neither the United States Government nor any agency thereof, nor any of their employees, makes any warranty, express or implied, or assumes any legal liability or responsibility for the accuracy, completeness, or usefulness of any information, apparatus, product, or process disclosed, or represents that its use would not infringe privately owned rights. Reference herein to any specific commercial product, process, or service by trade name, trademark, manufacturer, or otherwise does not necessarily constitute or imply its endorsement, recommendation, or favoring by the United States Government or any agency thereof. The views and opinions of authors expressed herein do not necessarily state or reflect those of the United States Government or any agency thereof.

HANFORD ENGINEERING DEVELOPMENT LABORATORY - Operated by Westinghouse Hanford Company, P.O. Box 1970, Richland, WA, a Subsidiary of Westinghouse Electric Corporation. Prepared for the USDOE, Assistant Secretary for Nuclear Energy, Office of Breeder Technology Projects, under Contract No. DE-AC06-76FF02170, BER No. AF-15-40-30. 


\section{DISCLAIMER}

Portions of this document may be illegible in electronic image products. Images are produced from the best available original document. 
From: MASF \& Auxlllary Systems Engineering

Phone: 6-9212 W/F-15

Date: AprII 5, 1985

SUbject: SENSITIZATION OF PARKER FITTINGS

To: $\quad$ P. S. Damm W/D-6

cc: So Arneson W/F-19
ML Grygiel W/F-34
S Guttenberg W/F-15
PR Praetorlus W/D-6
WM Ritter W/F-36
JC Tobin W/B-12
JB Waldo W/F-35
WW-ite/LB

Reference: 1) Letter, P. S. Damm to M. L. Gryglel, "Request for Problem Investigation, ORNL-UO-84-20," EQA:002, January 7, 1985.

In response to reference (1) the subject concern, as it relates to FFTF was investigated. Ferrules from three different lots were metallurgically examined. These lots were; 1) unused new stock, 2) unused old production (1977 or earlier) and 3) removed from chllled water service (installed during construction). Both unused lots were found to be fully sensitized and the ones removed from service were not. See attachment.

In addition, the Engineering department at Parker Hannifin, Huntsville, Alabama, was contacted which resulted in the following information.

Prior to 1978, ferrules were machined from bar stock and shipped. Starting with $3 / 8^{n}$ tube size in 1978, ferrules were full bore nitrided at $1100^{\circ} \mathrm{F}$ and allowed to cool slowly. These ferrules will all be fully sensitized and can be identifled by a dark color on the entire ID. The process has been progressively modifed to the point where for about the last year ferrules have been nitrided only at the tip at $800^{\circ} \mathrm{F}$ and then are quenched. These units should not be sensitized. There is no way to tell the current production from intermedlate runs which were tip nitrided at higher temperatures. They wlll all have a narrow dark band on the ID at the small end. Note, the ones examined which came from FFTF shop stock had narrow dark bands and were sensitized (see Attachment - Figure 1).

Engineering evaluation of this information as it applies to FFTF is as follows: For service in air, inert gases, or liquid metals, condition of the ferrules is not important. Any of the units described above will perform satisfactorlly. It is only in aqueous service that sensitization becomes important. A vast majorlty of the fittings that see water at FFTF 
P. S. Damn

April 5, 1985

Page 2

are used in the chilled and cooling water systems, which normally contain enough corrosion inhibitor that sensitized stainless will not be attacked. In the liquid rheostat system where a solution of soda ash is handled, no problem is expected since the high PH solution acts as a corrosion inhibitor. Even if sensitized stainless parts were present, they would not be attacked. The one area where acid is used is the cooling tower water treatment system, and problems were encountered with leaking stainless fittings. Accordingly, the entire acid injection system was reptumbed with plastic. As an aside, the acid injection system will be removed by Pace Item D-128, Cooling Tower Upgrade, which is scheduled for this fall.

Wholesale replacement of fittings at FFTF because they may contain sensitized ferrules is not warranted or recommended. The fact that we have not experienced a high failure rate, after years of operation, with the exception of the acid injection system, reinforces this position.

In the design and installation of any new equipment where acids are handled or where water temperatures may reach $600^{\circ} \mathrm{F}$ this potential problem will be addressed.

Mr. Wilber

W. W. Wilber Cognizant System Engineer

deg

Attachment 
MPE-85-09

From: Meteriats and Process Engineering

Phone: 6-0814

Date. March 28, 1985

Subjec: CONDITION OF FITTINGS

Ref.: Unusual Occurrence Report, OPNL-84-20-CT-84-2

To: W. W. Wilber (10)

CC: JC Tobin

MJG/LB/FiTe

At your request, ferrules from 316 SS Parker-hannifen compression fittings at the FFTF have been examined and evaluated to determine the metallurgical condition as related to carbide precipitation in grain boundaries (known as sensitization) and the implications this may have with regard to corrosion resistance. To accomplish this, two ferreles from new stock, two ferrules from old stock and two ferrules that had seen service were examined metallurgically. The samples were prepared for opticai metallography. They were vieweo in both the etched and unetched condition and analyzed on the scanning electron microscope (SEM) for elemental content.

It was confirmed that the ferrules from new stock had a 5 mil thick nitrided layer on the ferrule ID at the lead end and that the 316 SS ferrule material was in the sensitized condition, indicating 70 w resistance to aqueous corrosion. The material from old stock had no nitride layer but was in the sensitized condition indicating low resistance to aqueous corrosion. The ferrules that had seen service had not been nitrided and were not sensitized indicating high resistance to aqueous corrosion.

Figure 1 shows the microstructure of the ferrules from new stock at two magniffcations, $100 x$ and 500x, after the oxalic acid etch. It can be seen that there is gross carbide precipation in the 316 SS grain boundaries. The nitrided layer is visible in the 100X photomicrograph. The SEM elemental analysis of the layer did not detect heavy metal elements such as cobalt indicating that this was not a hardfacing overlay. The absence of heavy metal elements in this layer was taken as confirmation that the layer was a nitrided layer as indicated by Parker Hannifen. The hardened 1 ayer at the center had a microhardness of DPN 530 which would convert to Rockwell C51. The stainiess steel substrate by comparison was Rockwell B84 indicating an annealed condition. 
Figure 2 shows the etched structure of the old stock material. Again there is gross carbide precipitation in the grain boundaries or sensitization. However, there was no indication of a nitrided layer.

Figure 3 shows the structure of the material that had been in service. Although there is some evidence of carbide precipitation, the precipitates are widely scattered and do not envelop complete grains. So the material is not sensitized.

It is known that the corrosion resistance of austenitic stainless steel is affected by nitriding. The nitriding causes chromium to precipitate as chromium nitride, causing a depletion of the chromium in solid solution with iron with a concomitant decrease in corrosion resistance. - Sensitization also results in chromium depletion and a loss of corrsion resistance through carbide precipitation. As indicated in the referenced UOR, a problem with the nitrided type fittings came to light as a restilt of nitric acid service. The UOR rightly recommended that the nitrided fittings are unsuitable for use in chemical processing systems. However, we would expect the fittings that were not nitrided and not sensitized as those taken from FFTF service would perform in many aqueous environments. Also, we would expect that any one of the material groups would perform well in a dry gas environment. We would expect the 11 fe of the sensitized fittings would not only be affected by nitric acid but by any aqueous condition.

Mii. ‘́ Hexhen

M.'J. Graber

Attachments 


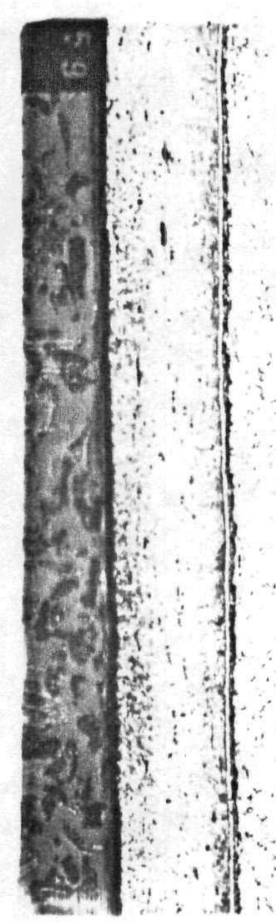

Oxalic Etch

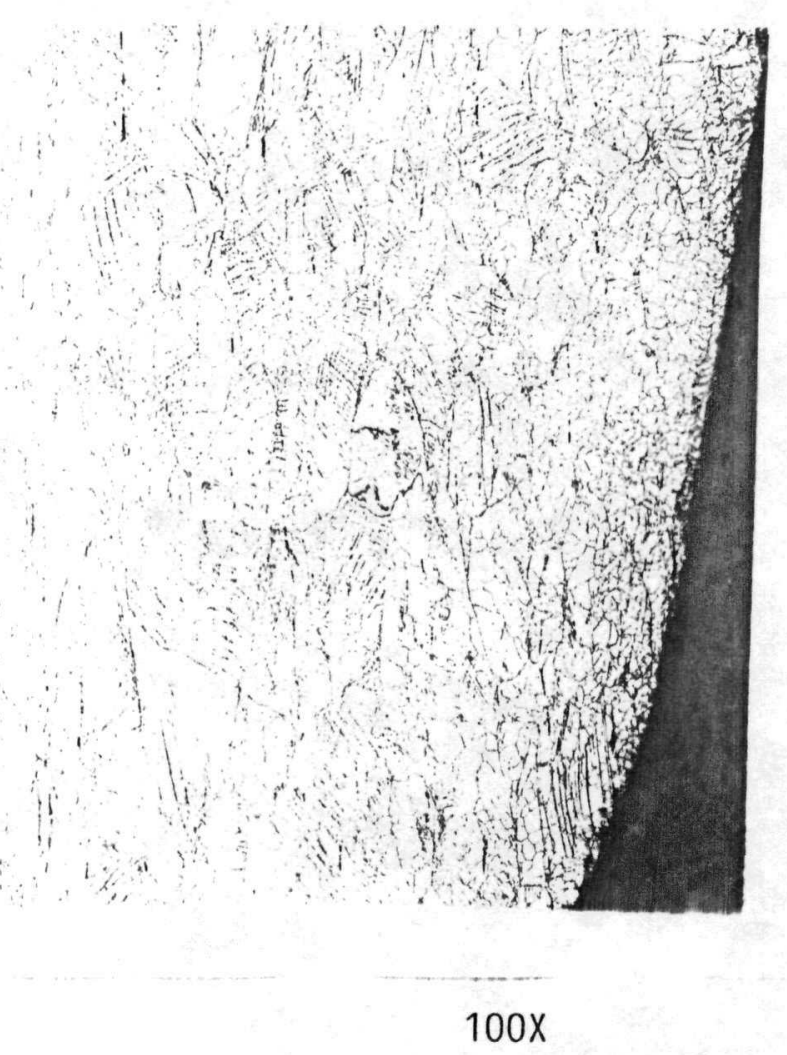

$100 x$

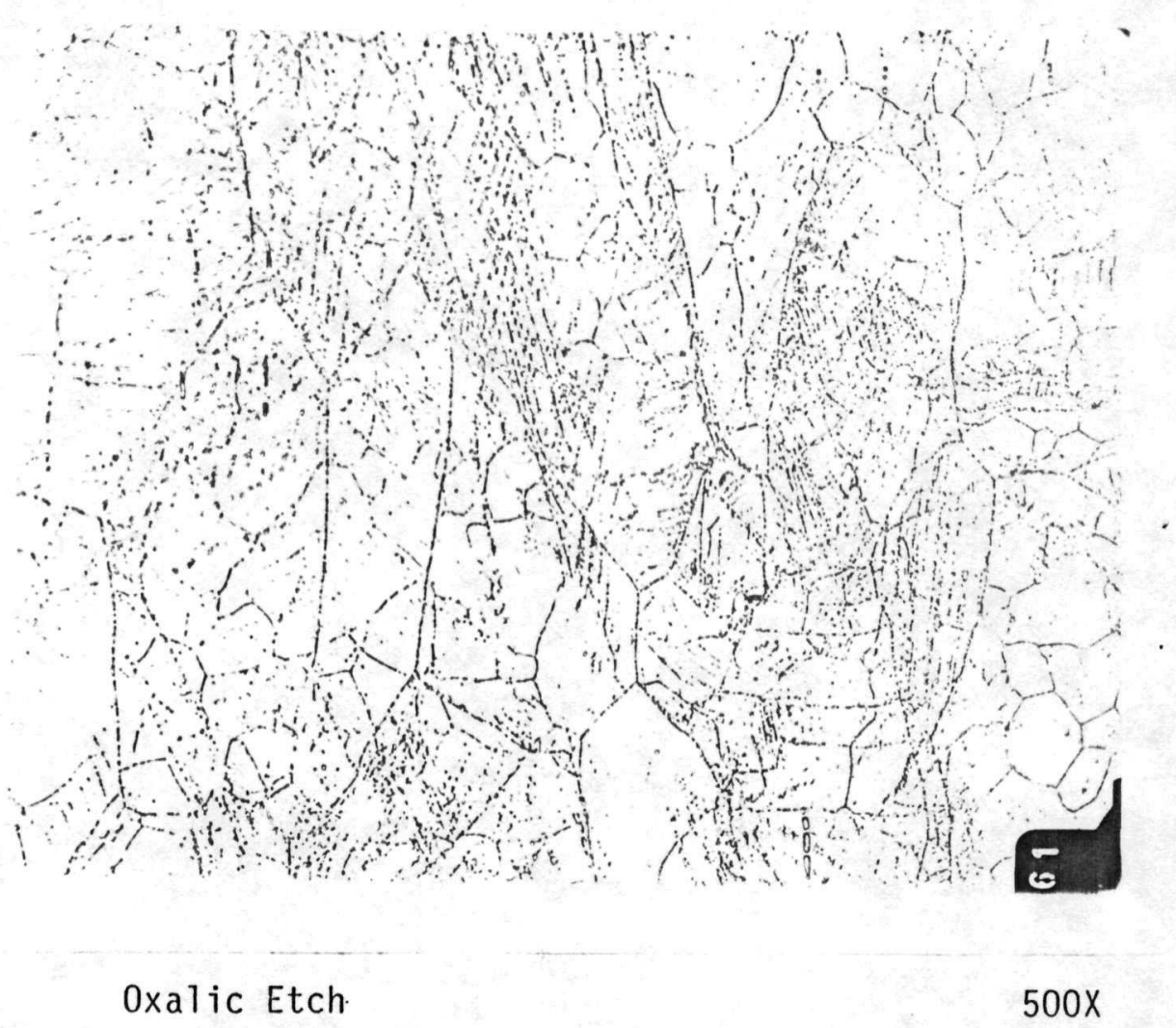

$500 x$

FIGURE 1. PHOTOMICROGRAPHS OF FERRULE FROM NEW STOCK. 


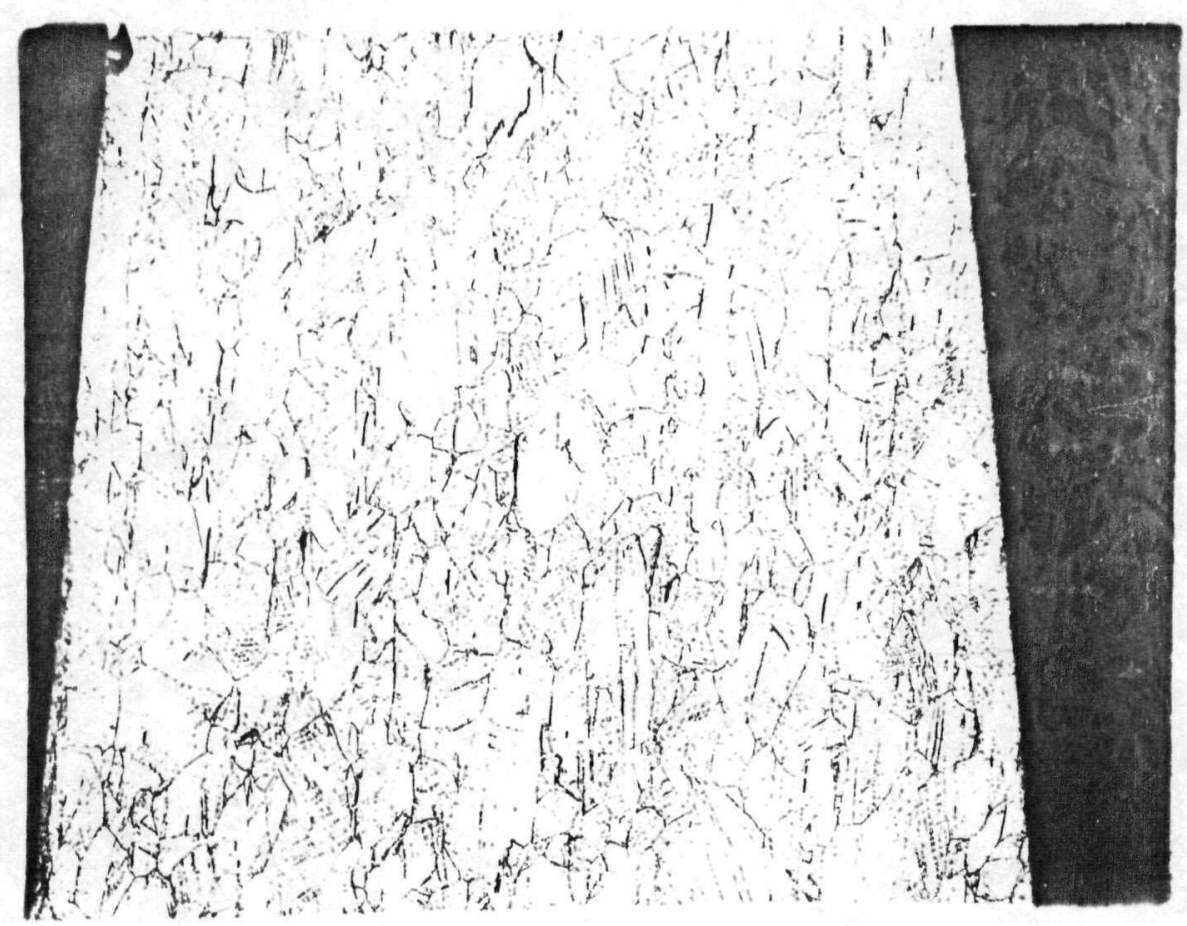

Oxalic Etch

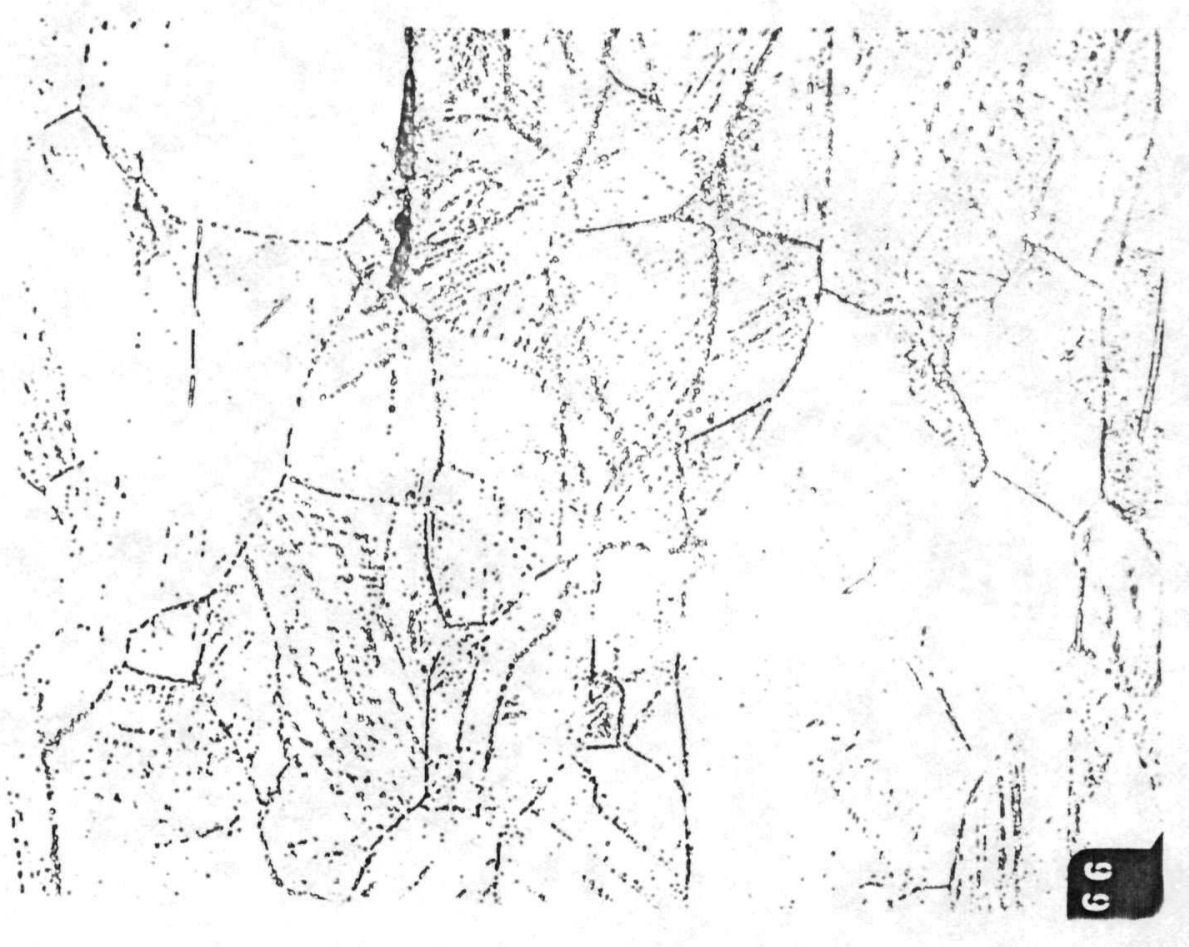

Oxalic Etch

FIGURE 2. PHOTOMICROGRAPHS OF FERRULE FROM OLD STOCK. 


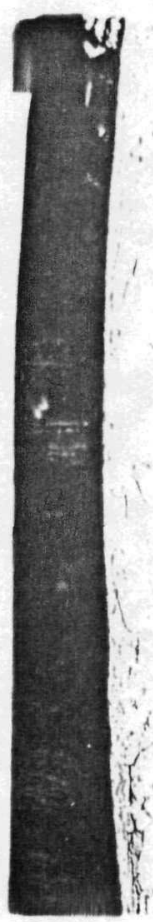

Oxalic Etch

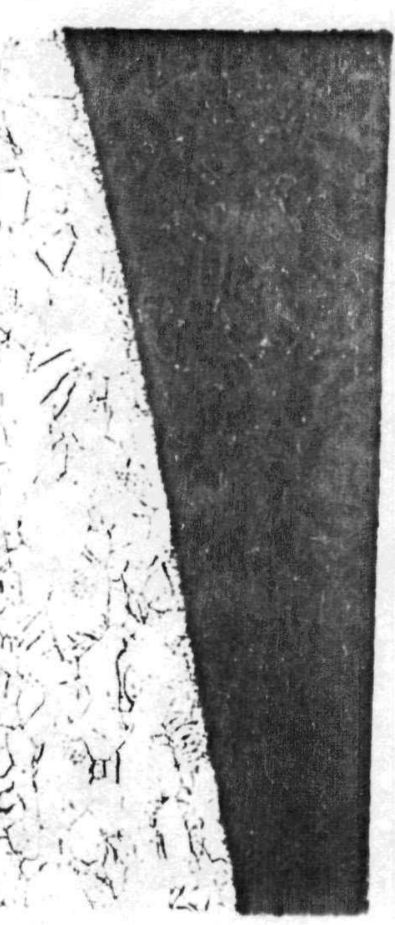

$100 x$

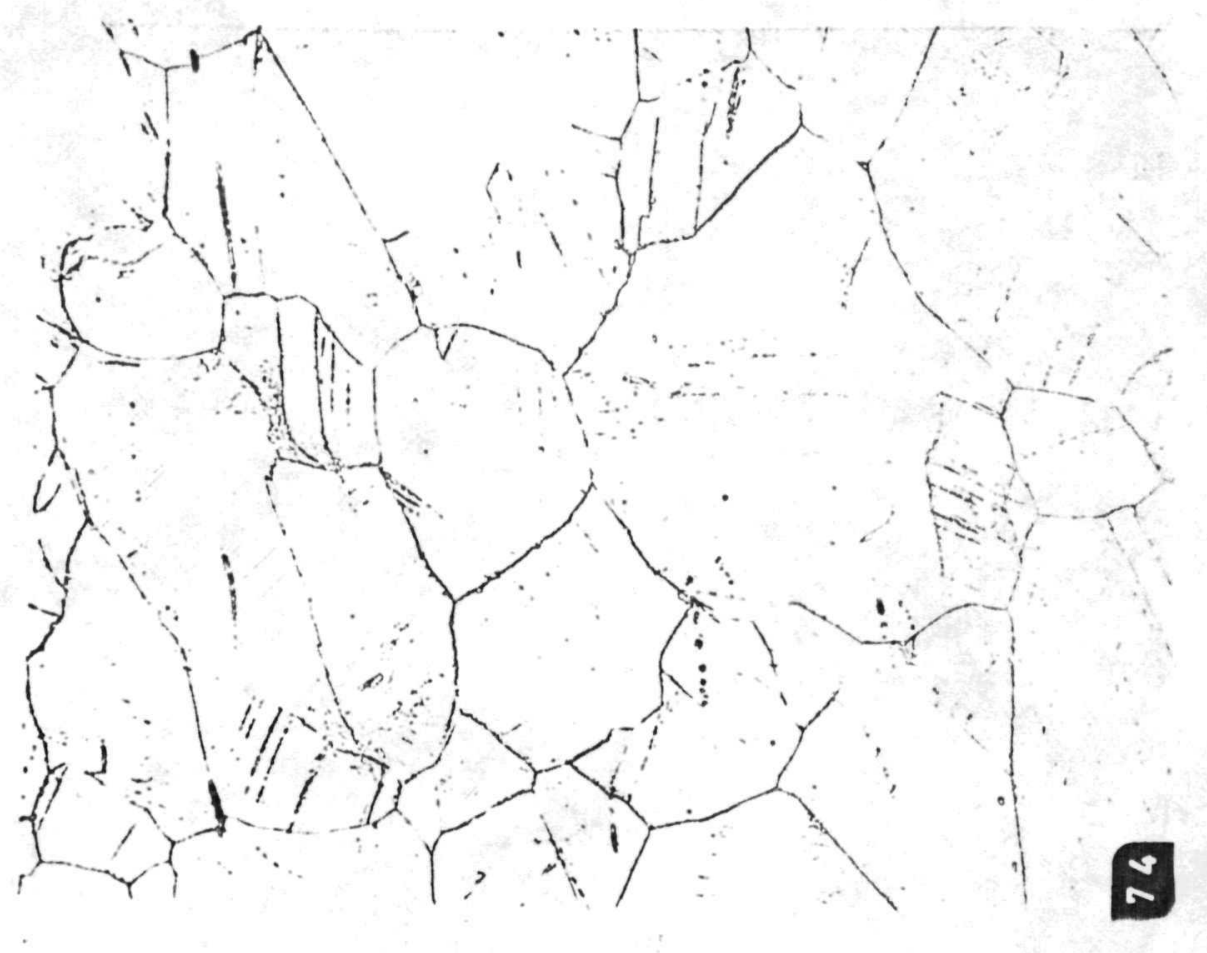

Oxalic Etch

FIGURE 3. PHOTOMICROGRAPHS OF FERRULE AFTER SERVICE. 